\title{
A methodology for attaining and assessing project success for rehabilitation projects
}

Received (in revised form): 2nd October, 2008

\begin{abstract}
Paul Watson
is Professor of Building Engineering and Head of Construction, Cost and Surveying at Sheffield Hallam University. His experience is varied, having spent some years in the construction industry as a project manager where he gained practical knowledge before entering the world of academia. He has not lost his industrial roots and has written numerous publications on construction- and surveying-related topics including authoring and co-authoring eight textbooks that have practical application. He has also designed degree courses that specifically address the requirements of building engineers and surveyors.
\end{abstract}

Correspondence: Paul Watson, Faculty of Development \& Society, Sheffield Hallam University, Owen Building, Howard Street, Sheffield S1 1WB, UK; Tel: + 44114225 5555; Fax: + 441142253179

\begin{abstract}
The paper explores the concept of project success for rehabilitation projects and its determination. The ultimate evaluation and decision as to whether a project has been a success must be based upon clear and measurable assessment criteria. The end products evaluation should be related to a clear and deliverable project brief. Knowing what is to be undertaken and its allocated timeframe is important, however having the necessary resources, and a thorough initial building evaluation is also vital. It is proposed to use a developed 'Project Life Cycle' model as a basis for demonstrating what, how and why certain key issues have to be addressed at the commencement of a project. If these key issues have been addressed before the project starts, its ultimate success is a more certain proposition. Contracting organisations, construction managers and project surveyors will find the issues discussed and the proposed 'Project Life Cycle' methodology of value. It can be adopted and utilised by project managers when they are considering how to structure and manage future projects. For example, when considering project management, the key aspects of time, cost and quality (or specifications) are always considered. These three aspects, however, should be overlayed with the concept of managing people. After all, it is people and not things that deliver project outcomes. This concept and its importance to project success shall be discussed and demonstrated. Journal of Building Appraisal (2009) 4, 181-189. doi:10.1057/jba.2008.36
\end{abstract}

\section{Keywords:}

control, control loop, project life cycle, triple loop learning

\section{INTRODUCTION}

It is clear that if we are to assess whether a project has been a success we must have clear and measurable assessment criteria. Further, the assessment criteria and the deliverables must be established at the start of the project as part of the project brief. Any conflict between the key criteria of time, cost and quality has to be agreed as part of the brief. On projects related to existing buildings such as adaptations, the establishment of agreed specific project deliverables is critical. The client needs to understand the impact of 
choice decisions they make. The following sections of this paper explore how a client can assist in the successful outcome of a project.

Project definition: As a starting point we need to define a project and the following range of criteria provides acceptable characteristics of a project:

- having a particular defined purpose which is not normally routine, or, by its nature, is unique;

- setting clearly defined start and end points, a time scale when the deliverables are required to be presented;

- an element of risk, because a project's unique nature touches upon the unknown, this is especially true when dealing with adaptations;

- an element of managing people's perception and their respective expectations;

- a range of complex activities involving key communication issues related to stakeholders.

With regard to the actual process of undertaking a project, the following are also defining characteristics:

- they have a set outcome and therefore projects are objective orientated;

- the purpose of creating/ascertaining something new, constructing a new structure or establishing new knowledge (these are not mutually exclusive);

- the possibility of challenging convention/traditional ways of working or knowledge (breaking existing paradigms, as in change management projects);

- an element of cross-discipline team working and/or collaboration;

- a requirement to manage people's expectations, values and contribution, not least the clients.

Project management requires a clear focus, so it is essential to commence with clearly defined project objectives in the form of a project brief, although this may need to be refined at a later date due to the uncertainty associated with some projects. In traditional buildings, the success of a project can be dependent on the extent and thoroughness of the initial Building Survey. Older buildings evolve over time and can contain hidden defects which tend to be uncovered during work on site. Serious defects can be found in closed structures such as in closed roof voids, under suspended floors and other inaccessible areas. These noted defects can lead to serious time delays and escalating costs which adversely impact on the success of a project. Therefore in constructing the project brief, it is very important that the surveyor takes all measures possible to minimise these risks by conducting a rigours investigation of the building. It is also vital that projects are considered in a holistic manner. One strategy for obtaining this holistic approach is by adopting a 'Project Life Cycle' methodology.

\section{PROJECT LIFE CYCLE}

'The project life cycle describes the sequence of phases through which the project will evolve. It is absolutely fundamental to the management [which incorporates control] of projects' (BSI, 2002). Project managers must effectively manage the lifecycle process as this will ensure that critical issues are not overlooked and that clients' requirements are followed. BSI (2002) notes that the project lifecycle should have 'Evaluation and approved points between phases'. This activity is usually referred to as undertaking 
quality checks or gate-keeping. Whatever the term, the function is a vital one as it links to the key management activity of control (covered later in this paper).

Figure 1 presents the 'Project Life Cycle' in a flow diagram format. If the project managers can understand the full implications of managing projects via a project life cycle then they are more likely to avoid the following threats to their success:

- the poor planning and scheduling of activities and resources utilised on the project;

- an over optimistic expectation by the client, which would ultimately lead to a failed project or at least the perception of a failed project;

- a general lack of co-ordination of resources throughout the project;

- a lack of management expertise and the application of appropriate management tools/ techniques;

- unknown and unforeseen circumstances which occur before and during the project's lifecycle, due to the unique nature of most projects.

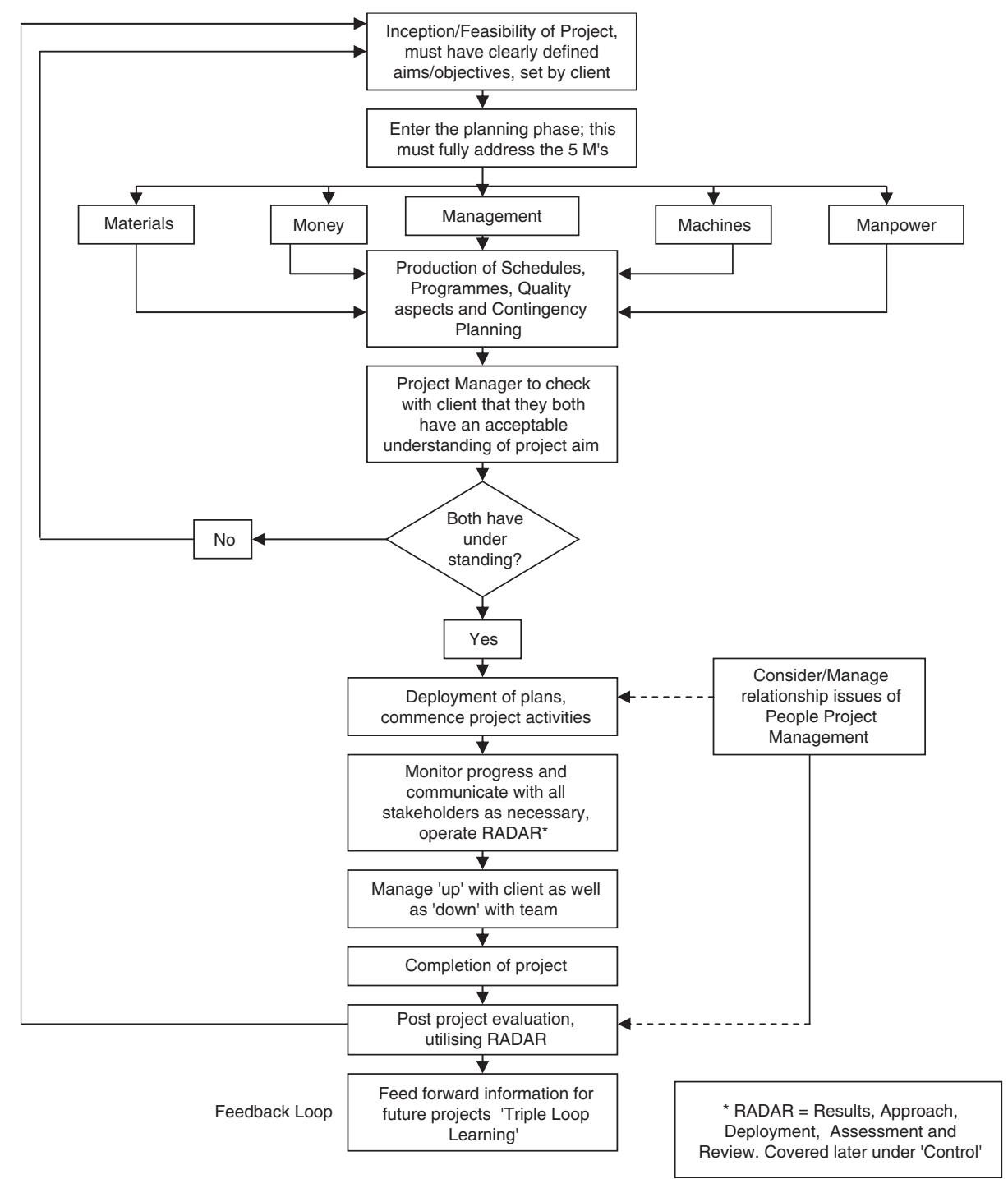

Figure I: Project management lifecycle flow diagram (diagram produced by author) 
With regard to unforeseen circumstances, on adaptations these may be overcome as indicated above by conducting a thorough survey. This activity may include an extensive desktop study to trace the evolution of the structure and the establishment of any changes. Further, the opening up of closed voids prior to the survey and the utilisation of nondestructive testing may be appropriate. Were this not possible, and the inspection took place on site, the schedule, however, should allow for the inspection activity and any necessary remedial work which requires costing. One must remember that in the case of listed buildings both the remedial work and the opening up of the works may also require listed building consent.

Although planning and scheduling are advocated activities one must not forget the unique nature of some projects, so it is important for the planner to employ the concept of flexible planning. This would incorporate '... an overall time plan of the stages' (Phillips and Pugh, 2005). In project management, the objectives have to be linked to the available resources allocated to the project and planning schedules produced. Delamont et al. (1997) advocate the production and use of a 'plan and work schedule [and] these will need regular review by the team'. The project manager needs to take time to think through how the project will be 'managed', who will be involved and how to get them to 'engage' with the project in hopefully an enthusiastic manner.

In the introduction section of this paper, the purpose of establishing a rationale for having a clear focus has been presented. This rationale can be further underpinned by thinking of projects as having a definitive 'Project Life Cycle'.

A 'Project Life Cycle' consists of:

- Conception: This may be an idea leading to the formulation of specific aims and objectives;

- Planning: Thinking through and linking the critical phases/activities/resources required for the successful completion of the project, but it is not a once only activity and it must continue throughout the projects lifecycle;

- Execution: The implementation phase this will involve some re-planning and coordinating of activities (flexible planning);

- Closure: Completion linking back to conceptions, aims and objectives and hopefully learning from the experience.

The critical starting point in Figure 1 is the establishment of the project's aims and objectives, or what are the expected deliverables as determined by the project brief, as agreed by all stakeholders, as previously noted, this will determine the extent of a projects success. Figure 1 also notes the use of the RADAR Concept as a driving and controlling force.

\section{CONTROLLING THE PROJECT}

A project manager has to be concerned with the efficient and effective use of their available resources, for example, time and money, in the attainment of the aims and objectives contained within a specific plan based upon the set and agreed project brief. The plan being the method deployed in order to achieve/complete the pre-determined aims and objectives.

Project managers determine the broad lines of operation, the strategy or general programme, choose the appropriate methods, and sometimes the materials for the most effective and efficient actions. So, planning relates to how, when and where the project is 
to be carried out. To be really effective, planning must be simple, flexible, balanced and based upon accurate information. Planning is an important tool for the project manager, requiring intense application and precise attention to detail. As purported by Cryer (1996) '... you need to map out some sort of plan for your programme of work ahead ... [the plan] can provide a sense of security in that where you are now and where you are going have been thought about and are documented ... [the plan is] also something to display'.

Having a plan is not an end in itself; the plan is only a starting point in trying to control the project. A successful project manager has also to engage in the 'Control Function'. After all, as noted by Cryer (1996) 'Detailed plans inevitably need regular amendment'. This point is particularly pertinent when engaged on adaptation works.

So, let us consider control as applied within the framework of a project. Control is exercised by the feedback and feed forward of information upon actual performance when compared with the pre-determined plan; therefore planning and control are very closely linked. Control is the activity which measures deviations from planned schedules, activities/objectives and further initiates effective and efficient corrective actions based upon a valid comparative analysis.

Control cannot be a bolt-on activity, it must be inherent form the initial conception of the project and of course based upon a valid survey and detailed brief. This requires the project manager to be specific about their aims and objectives. Even this is not sufficient, however, and the aims and objectives must be woven together into a holistic representation of the project in order to deliver the clients requirements. A project manager must understand two important concepts of applying the Dynamic Closed Loop Feedback Control mechanism (see Figure 2); the first is Cycle time. Cycle time refers to the duration of time taken for the information to circulate around the loop. Cycle times must be as short as possible. Also the Control mechanism must be applied at frequent appropriate intervals.

The second concept relates to the 'Quality' of information circulating within the loop. Poor quality information circulating rapidly is of little value to the project manager. If the project manager has good quality information circulating rapidly and frequently, there can be efficient and effective control of the project and a successful outcome is more likely.

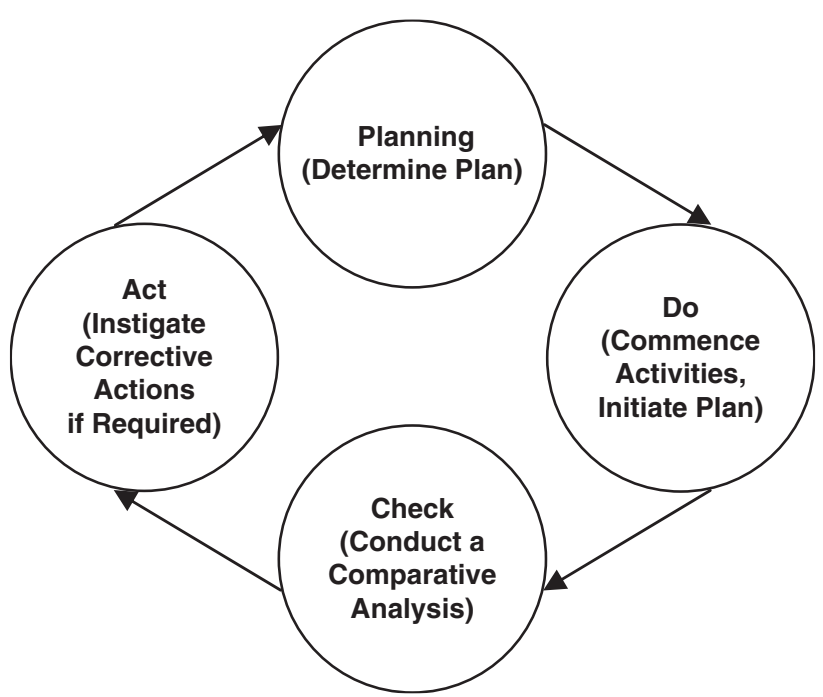

Figure 2: Deming dynamic loop control cycle (adapted from Griffith and Watson, 2004) 


\section{CONTROL CYCLES}

The concept of the 'Plan, Do, Check and Act (PDCA) control cycle' can be simply defined as establishing the project objectives, based on the project brief and then determining the appropriate methods of reaching the set goals (Plan), implementation of the Plan (Do), check the effect of the implementation by comparing the actual results with the Plan (Check) and taking any appropriate corrective action (Act). PDCA is a continuous process applicable to any project (see Figure 2).

The PDCA approach in relation to a project involves the following:

- Plan: Identify needs and expectations of the stakeholders especially the client and then set strategic objectives;

- Do: Deploy and operate defined processes as determined by the plan;

- Check: Collect performance results and monitor and measure the processes, review, analyse, and compare actual results with the plan;

- Act: Continually improve processes and performance, based upon a comparative analysis and if required instigate control functions.

The information contained within the control loop must:

- be separated according to areas of responsibility/accountability;

- present results in a consistent, readily understood and useful manner for the project manager, so appropriate actions can follow;

- represent appropriate and valid time periods for instigating effective actions as you cannot have retrospective corrective actions;

- be available in time for effective decisions to be taken;

- divert the minimum energies from primary functions/objectives, one must consider the 'Law of Diminishing Returns' and associated 'Opportunity Costs';

- demonstrate clearly the deviations from the pre-determined plan (and project brief) so the control functions can be deployed.

If one considers in more detail the PDCA control cycle, it is possible to improve on this process when applied to projects.

A project manager needs to employ the concept of 'Triple Loop Learning', to do this they must start with their plan and continually monitor it against actual results, and think and reflect upon deviations before instigating any actions. This process will involve 'conflictual questioning' and Engstrom (2001) advocates that this is not a barrier to learning, but will in fact lead to sharper and more focused questioning of results and possible resulting actions. For the project manager, it is essential to engage in 'Triple Loop Learning', thus improving their performance. One method of empowering the project manager to use triple loop learning is by using RADAR as previously noted on the Project Life Cycle flow chart in Figure 1.

\section{RADAR}

At the heart of the European Foundation for Quality Management Excellence Model (EFQM, EM) lies a specific logic and this is known as RADAR. It consists of the following elements - Results, Approach, Deployment, Assessment and Review. EFQM's RADAR model mechanism is related to Deming's continuous improvement philosophy of Plan, Do, Think and Act. More importantly, the RADAR process is driven 
by a self-assessment approach. Thus, the application of 'RADAR' and hence 'Triple Loop Learning' involves:

- determining the results that one is aiming for (project aims/objectives) based upon a detailed project brief;

- the next phase is to 'plan' and develop an integrated set of sound 'Approaches' (how the project manager will achieve their set results) again for adaptations works this has to be based on a thorough survey;

- the next action is to 'Deploy' the approaches established during the 'Approaches' phase, that is, the implementation of the plan. But always related back to the project brief;

- how one engages in triple loop learning is by the 'Assessment and Review' phase. This will be based upon monitoring and analysis of the results achieved and ongoing learning activities (conducting a comparative analysis between what was required and what was achieved);

- finally, to identify, prioritise, plan and implement improvements where and when required, to ensure the projects objectives are attained.

RADAR will enable the project manager to establish whether the approaches used were in fact appropriate for the attainment of the set results (delivering the briefs requirements). It could well be that the approaches were not in fact the correct ones for achieving the set aims and objectives. This could be the case if a detailed survey was required but not conducted. Figure 3 provides a pictorial representation of the Plan, Do, Think and Act cycle linked to the 'Triple Loop Learning' of RADAR. If the project manager employs the concept of RADAR, they will have a greater chance of achieving a successful outcome because the starting point is 'Results' that is the project brief.

The application of 'Triple Loop Learning' is essential to developing and managing the project. The concept instils a mind-set of thinking, planning, monitoring, acting and reflecting throughout the whole process. Thus, it applies a personal dynamic approach to a creative activity where self-motivation and effort are perhaps the greatest resources to delivering a successful outcome.

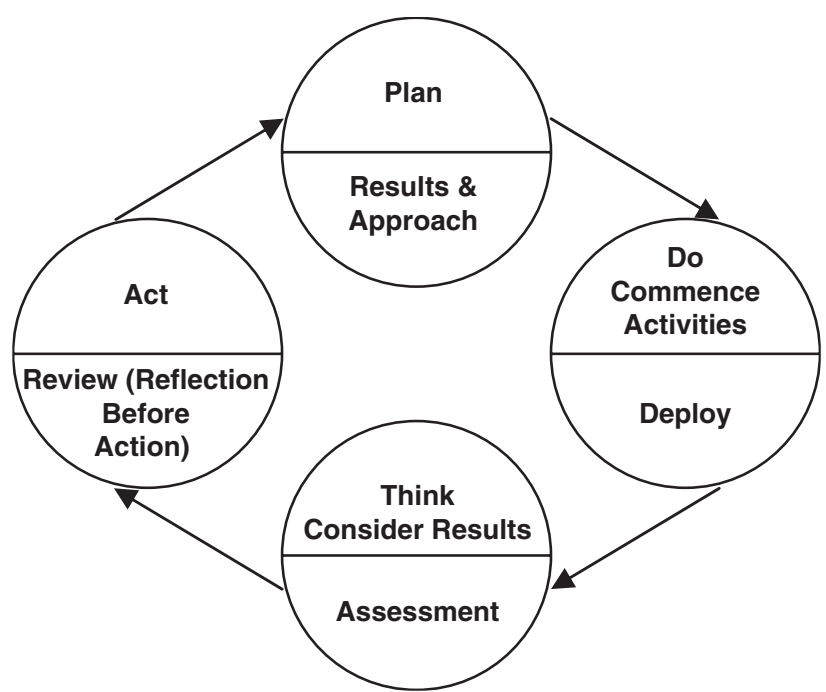

Figure 3: Matching of Plan, Do, Think and Act cycle to RADAR (diagram produced by author) 


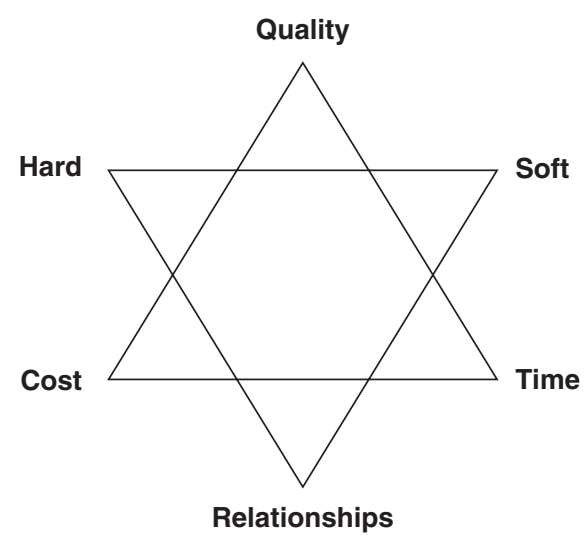

Figure 4: Unique features of project management (Watson et al., 2008)

The ability to plan, act and reflect must become intrinsic to the project manager's approach and activities. The task of delivering the project from its conception to conclusion should be actively managed.

Thus far, we have concerned ourselves with the hard criteria of time, cost and quality and their respective control. We must never forget that projects, however, are produced by people and during adaptations their contribution must not be undervalued. So, Figure 4 presents a true reflection of the totality of managing projects.

\section{INFLUENCING AND PERSUADING THE TEAM}

Figure 4 notes that the project manager has to manage relationships between people, including all the stakeholders related to the project, both internal and external. The hard soft relationship management is impacted upon by 'management style', and this important issue must not be overlooked by the project manager.

The project manager's role requires them to both influence and persuade personnel. Therefore, they have to be familiar with 'push' and 'pull' managerial styles:

- Push: This is pushing through management decisions based upon the use of hierarchical authority;

- Pull: This is decision making through consultation and joint participative inclusive decision making.

Project managers will find themselves in situations where they may want to consult and be 'inclusive', but time constraints may not permit, and they have to make a decision at that point in time based upon the knowledge they have. The key to good project management is 'consistency'. Given a certain situation (you) the manager will function in a certain way and your team will acknowledge and accept this.

The project manager needs to understand that one approach is not better than the other. In most circumstances, a 'Pull Style' is preferable, but the key is consistency of approach.

\section{CONCLUSIONS}

It can be seen throughout this paper that one of the critical factors in any project is the determination of a valid project brief, this may depend upon a prior survey to fully determine the critical issues. The process of managing a project is dynamic, self-led and 
involves the adoption of the 'Triple Loop Learning' process. This requires the project manager to engage in a continuous cycle of planning, doing, checking, thinking and acting. In this way, the manager is able to decide on a required course of action, monitor their progress and motivate themselves and their team to continue on course.

In short, the ability to develop and deliver a successful project is all about consciously and actively 'managing' based upon sound project management concepts and using project management tools, especially the control function. The process of people management and their contribution to a project's success or failure, however, must not be underestimated by the project manager.

\section{References}

British Standard Institution. (2002) Project Management Part 1: Guide to Project Management, British Standard Institution, Milton Keynes.

Cryer, P. (1996) The Research Guide to Success, Open University Press, Maidenhead.

Delamont, S., Atkinson, P. and Parry, O. (1997) Supervising the PhD: A Guide to Success, The Society for Research into Higher Education and Open University Press, Buckingham.

Engstrom, Y. (2001) 'Expansive learning at work: towards and activity theoretical reconceptualization [online]', Journal of Education and Work, 14(1), 133-156, available from: EBSCO Business Source Premier — Database (accessed 5th November, 2004).

Griffith, A. and Watson, P. (2004) Construction Management: Principles and Practice, Palgrave Macmillan, Basingstoke. Phillips, E.M. and Pugh, D.S. (2005) How to Get a PhD: A Handbook for Students and their Supervisors 4th edn, Open University Press, McGraw-Hill Education, Maidenhead.

Watson, P., Gibson, D., Hanney, N., Rushforth, P., Smith, S., Walsh, C. and Workman, G. (2008) Surveying and Engineering: Principles and Practice, Blackwell Publishing, Oxford. 